\title{
Strengths and vulnerabilities of Australian networks for conservation of threatened birds
}

\author{
Tim Q. Holmes, Brian W. Head, Hugh P. Possingham and Stephen T. Garnett
}

\begin{abstract}
We analysed the supportive social networks associated with the conservation of six threatened Australian bird taxa, in one of the first network analyses of threatened species conservation programmes. Each example showed contrasting vulnerabilities. The Alligator Rivers yellow chat Epthianura crocea tunneyi had the smallest social network and no real action was supported. For the Capricorn yellow chat Epthianura crocea macgregori the network was centred on one knowledgeable and committed actor. The orange-bellied parrot Neophema chrysogaster had a strongly connected recovery team but gaps in the overall network could limit communication. The recovery teams for the swift parrot Lathamus discolor and Baudin's black-cockatoo Calyptorhynchus baudinii had strong links among most stakeholders but had weak ties to the timber industry and orchardists, respectively, limiting their capacity to manage threatening processes. Carnaby's black cockatoo Calyptorhynchus latirostris seemed to have the most effective social network of any of the taxa studied but may be vulnerable to skill shortages. In each case the network analysis pointed to gaps that could be filled to enhance the conservation effort, and highlighted the importance of recovery teams. The research suggests that formal network analysis could assist in the design of more effective support mechanisms for the conservation of threatened species.
\end{abstract}

Keywords Connectedness, governance, recovery teams, social network analysis, threatened species

\section{Introduction}

uch has been written about the biology of Australian 1 threatened birds; however, less information is available about the social and organizational processes involved in their management. These social processes primarily refer to the cooperative spaces where participants strive to achieve a common purpose (in this case, the conservation of the threatened species). The key participants are the decision-

Tim Q. Holmes and Hugh P. Possingham Centre for Biodiversity and Conservation Science, The University of Queensland, St Lucia, Australia

BRIAN W. HEAD Institute of Social Science Research, The University of Queensland, St Lucia, Australia

STEPHEN T. GARNETT (Corresponding author) Research Institute for the Environment and Livelihoods, Charles Darwin University, Darwin, Northern Territory 0909, Australia. Email stephen.garnett@cdu.edu.au

Received 14 March 2016. Revision requested 1 April 2016.

Accepted 18 April 2016. First published online 8 November 2016. making actors within an organizational framework trying to solve collective problems. The participants in an action situation (Ostrom, 2005) for a threatened species may include those actively involved in the conservation of the bird or those with an interest in, or concern about, the bird or a related issue. They may be individuals, or representatives of NGOs, community groups, land owners, governments or corporate actors, interacting for a range of reasons, including obtaining or disseminating information, solving problems, negotiating, making decisions, collaborating and seeking physical resources (Ostrom, 2005; Jepson et al., 2011). The key components of these action situations include key participants, interorganizational collaborations and social networks. Here, we focus on the social networks of key participants and seek to determine how such networks may influence the effective management of biodiversity protection schemes for threatened birds. To our knowledge this is one of the first analyses of social networks concerned with the conservation of threatened species (see also Ainsworth et al., 2016; Jepson, 2016).

In the context of conservation policy and management a social network comprises a set of actors with socially meaningful ties that represent relationships such as those arising from shared decision making, seeking or providing advice, or borrowing or lending resources. Social networks can be useful as a basis for establishing informal collaborations and for working across critical functional, hierarchical or geographical boundaries (Cross et al., 2002a,b). Links among actors at multiple levels have also been found to result in greater capacity for monitoring, improved ecological understanding and promotion of appropriate incentives (e.g. power sharing, distribution of economic benefits; Armitage et al., 2012). Increasingly networks are being viewed as an evolving form of governance supplementing formal and hierarchical approaches (Stoker, 1998; Keast et al., 2014). However, like all forms of governance, there is variety among networks in terms of their processes, membership, resources and legitimacy (Adger et al., 2005; Koliba et al., 2011). As governance instruments, all networks involve some form of trade-off (Alexander et al., 2015), so there is no universal ideal, but analysis of networks can help make such trade-offs explicit and facilitate assessment of how they are influencing the governance issues of concern.

Social network analysis has been applied to both the physical and social sciences, with examples including fields as diverse as the spread of happiness (Fowler \& Christakis, 2008), the study of animal behaviour (Wey et al., 2008), and the internet as a social network (Otte \& Rousseau, 2002). 
Social network research has become more widely undertaken, with at least five peer-reviewed journals (Social Networks, Computational Social Networks, Social Network Analysis and Mining, International Journal of Social Network Mining, Journal of Social Structure) now dedicated to publishing social network research. Social network analysis identifies patterns of relationship among people and organizations, and can represent them both visually and mathematically. In general, it has proved useful for providing a formal mechanism for representation, measurement, and modelling of relational structures. Although there is always a risk that methods may be misapplied or misinterpreted, resulting in inappropriate conclusions, the risk can be minimized through careful choice of methods and applications in network analysis (Butts, 2009). In recent years social network analysis has been employed by natural resource management and conservation biology researchers to improve understanding of how actors collaborate and coordinate management efforts (Tompkins \& Adger, 2004; Bodin et al., 2006; Lauber et al., 2008; Woodward, 2008; Chilvers \& Evans, 2009; Crona \& Hubacek, 2010; Lukasiewicz et al., 2013). This work has also recognized the importance of stakeholders as influential environmental decision makers (Prell et al., 2009) and has shown that social network analysis can make valuable contributions to conservation outcomes as a tool for exploring the relationships between stakeholder network structures and the implementation of conservation actions (Vance-Borland \& Holley, 2011).

For the management of Australia's threatened birds, relevant social networks contain stakeholders within designated management areas and can be used to mobilize and maintain co-management of individual threatened species. Although the effectiveness of recovery plans has sometimes been questioned (Bottrill et al., 2011), recovery teams, which are associated with some, but not all, recovery plans, have been influential within these networks (Holmes, 2014). Species recovery teams are collaborations of stakeholders who coordinate the implementation of the recovery plans. Key roles of recovery teams include coordination, communication (including to their broader networks) and inclusion of stakeholders (Holmes, 2014). The objectives of this study are to describe the networks established among those involved in the conservation of threatened birds, how they contribute to solving the problems faced in threatened species conservation, and the value that can be derived from analysing them.

\section{Methods}

Network analysis is undertaken to understand the pattern of relations among individuals and organizations with a direct interest in a topic of common interest (Wasserman \& Faust, 1994; Bodin \& Crona, 2009). Here we have analysed the networks associated with the conservation of six threatened bird taxa in Australia. The analysis helped identify the strength and nature of organizational connections in the political landscape by quantifying the intensity of relationships and interactions among the actors (Holland, 2007). Some of the key assumptions and underlying concepts of our analysis include the following (Wasserman \& Faust, 1994): relationships among actors are important, actors and their actions are seen as interdependent rather than independent, relational ties between actors are channels for the transfer of resources (either material or nonmaterial), and network models help us to conceptualize a range of weak to robust patterns of relations among actors.

Based on the analyses provided by Bodin et al. (2006), it is possible to investigate and measure several relational factors that may have impacts on learning, leadership and trust, which are relevant to the contributions of social networks for managing natural resources such as threatened species. These characteristics may change or evolve over time, and some factors are likely to be more significant for certain contexts than others. The analysis below adapts the categories provided by Bodin et al. (2006) as follows:

- Centrality: the number of links to an individual actor. This can affect the capacity of a group to experiment with new ideas or coordinate actions.

- Density: the number of links divided by the number of actors in the network. This is useful for understanding the variety of skills in a group and whether it will be affected by the loss of individuals.

- Reachability: when there are connections between two actors regardless of how many other actors fall between them. This can affect communication within a group.

- Betweenness: the percentage of all geodesic paths from neighbour to neighbour that pass through an actor. This can help in understanding the diversity of skills and levels of trust within a group.

- Subgroups: actor groups that can be identified among the full component of individuals within the network. This can indicate the extent to which alternative views are likely to be available to generate innovation.

These six factors, all of which have relevance to various aspects of threatened species governance, have been combined in Table 1 as a framework for assessing the key attributes of the six species conservation networks that are the focus of this study.

\section{Case study bird taxa}

We examined the social networks for six threatened birds (the Alligator Rivers yellow chat Epthianura crocea tunneyi, the Capricorn yellow chat Epthianura crocea macgregori, the orange-bellied parrot Neophema chrysogaster, the swift parrot Lathamus discolor, Carnaby's black-cockatoo Calyptorhynchus latirostris, and Baudin's black-cockatoo 
TABLE 1 Attributes potentially influencing the effectiveness of social networks for the management of natural resources, and related metrics (derived from Bodin et al., 2006).

Attribute
Collective memory/experiences: commonality in history strengthens
network cohesion in times of change \& uncertainty.
Diversity: variation in types of actor \& of knowledge within the network
\& potential for innovation is obtained from a degree of separation be-
tween groups. It is also important for fostering the resilience needed to
adapt to unexpected change.
Redundancy, or the extent to which links are replicated, helps buffer a
network against loss of individuals.

Learning: knowledge can be increased \& improved continually if there are strong ties \& access to many actors to receive \& disseminate information.

Adaptive capacity: new challenges or knowledge require a timely response for networks to be effective.

Trust: cooperation is facilitated by high levels of mutual confidence among actors.
Network metric characteristics

Density: high; many links to others in the network

Reachability: high; access to many individuals

Density: low; a dispersed network can increase the variety of skills available

Betweenness/subgroups: low; groups within a network need a certain degree of separation to facilitate innovation

Density: high; with many links the loss of single actors is less disruptive

Betweenness: low; low levels of betweenness of single actors reduces the vulnerability of a network to fragmentation

Centrality: low; decentralized management encourages experimentation \& experiential learning

Reachability: high; access to many actors increases knowledge pool Betweenness: low; learning is facilitated by close links within subgroups to transfer knowledge

Centrality: high; concentration of links increases capacity for coordination of actions

Density: low; actors with fewer links have greater political flexibility \& are subject to lower levels of peer pressure

Reachability: high; collective action requires multiple actors to collaborate

Density: high; many links foster feelings of belonging \& group identity

Betweenness/subgroups: high; low levels of separation among groups can assist the development of trust
Calyptorhynchus baudinii), taking into account the following important contextual characteristics: type of organization involved in threatened bird conservation; programme structure; number of partners and participants; habitat/ecosystem; threats; land tenure; scale; and jurisdictional overlap. In selecting the six taxa we chose three sets of pairs with similar attributes: (1) two subspecies of the same species that have similar ecology and are localized in distribution but separated geographically, and in separate jurisdictions; (2) two distinct species with different ecologies that both migrate and occur in multiple jurisdictions; and (3) two closely related species of similar appearance that have overlapping distributions under a single jurisdiction. The study of these paired examples facilitated a more nuanced exploration of the interplay between ecological, jurisdictional and social factors underlying the role and effectiveness of networks supporting the recovery teams.

The Alligator Rivers yellow chat is a subspecies of the endemic yellow chat (Keast, 1958), a small insectivorous bird recorded from river catchments east of Darwin in the Northern Territory, where it is known from only a small number of sites (Fig. 3.2 in Schodde \& Mason, 1999; Armstrong, 2004). It inhabits seasonally inundated alluvial floodplains that support a sparse cover of grasses, herbs and sedges, and stands of mangrove around tidal channels
(Armstrong, 2004). It is categorized as Endangered under both the IUCN criteria (Garnett et al., 2011) and the Environment Protection and Biodiversity Conservation Act 1999 (Department of the Environment, 1999). The main identified threats to the Alligator Rivers yellow chat are habitat degradation by introduced herbivores, such as cattle, feral pigs and water buffalo, invasive plants and saltwater intrusion; inappropriate fire regimes; and predation by feral cats (Commonwealth Threatened Species Scientific Committee, 2008). Coordination of conservation management for this subspecies has been left to individuals within the Northern Territory's Department of Land Resource Management and the Parks and Wildlife Commission as well as the management authorities of Federally controlled Kakadu National Park. At the time of the research there was no conservation activity directed specifically at the subspecies.

The Capricorn yellow chat is another subspecies of the yellow chat (Keast, 1958), with a localized distribution in the Fitzroy River Delta near Rockhampton, central Queensland, and several sites adjacent to Broad Sound, $150 \mathrm{~km}$ to the north, where it inhabits seasonally inundated marine plain wetlands (Houston \& Melzer, 2008). It is categorized as Endangered under the IUCN criteria (Garnett et al., 2011), and Critically Endangered under the 
Environment Protection and Biodiversity Conservation Act 1999 (Department of the Environment, 1999). The Capricorn yellow chat is potentially threatened by habitat degradation caused by grazing, trampling and digging by mammalian herbivores, invasion by exotic pasture grasses, alteration of natural water flows, expansion of industrial operations, and wildfire (Houston \& Melzer, 2008). There was a loose collection of mainly non-government actors who had a common interest in the subspecies and its habitat and who undertook population monitoring, surveys and research. Within this group was an ecologist who championed the implementation of the recovery plan for the taxon. This person primarily focused on ecological research and was the primary contact for issues relating to the subspecies.

The remaining four species all had recovery plans, which identified necessary research and management actions to stop the decline of a threatened species, support its recovery and enhance its chance of long-term survival in the wild (Department of Sustainability, Environment, Water, Population and Communities, 2013). For each of these recovery plans there were recovery teams that coordinated implementation of the plans.

The orange-bellied parrot is a small, largely green, parrot of coastal habitats, including eucalypt forest (for breeding), salt-marshes, coastal dunes, pastures, shrublands, estuaries, islands, beaches and moorlands. It breeds in south-west Tasmania and migrates to south-eastern South Australia and Victoria for the winter (Orange-bellied Parrot Recovery Team, 2006). It is categorized as Critically Endangered under both the IUCN criteria (BirdLife International, 2015b) and the Environment Protection and Biodiversity Conservation Act 1999 (Department of the Environment, 1999). The reasons for the species' decline are not clear but it was thought at the time to be threatened by fragmentation and degradation of over-wintering habitat by drainage, grazing, agriculture or urban development, and inappropriate fire regimes in the breeding range (Orange-bellied Parrot Recovery Team, 2006). The Orange-bellied Parrot Recovery Team was established in 1983 and comprised 15 members. The role of coordinator was rotated annually between representatives of the three state governments, the jurisdictions of which share the species' distribution. The team recognized the importance of the broader network, which was acknowledged in its terms of reference: the team 'recognized the important contributions and interests of this broader Network and communicated to individuals through email updates. Network members were also informed of, and invited to, all open team meetings. The Network membership was not limited and new members were included by the team as required.'

The swift parrot is a small green and red monotypic parrot of forests and woodlands, with seasonal use of habitat in different parts of the landscape in both its breeding and non-breeding range. It breeds on the east and south-east coast of Tasmania during the summer and migrates to mainland south-eastern Australia for the winter, primarily to Victoria and New South Wales (Swift Parrot Recovery Team, 2001). It was categorized at the time as Endangered under both the IUCN criteria (BirdLife International, 2015a) and the Environment Protection and Biodiversity Conservation Act 1999 (Department of the Environment, 1999). The greatest threat to survival of the swift parrot is habitat loss through land clearing for plantation development and intensive native forest silviculture (Saunders \& Tzaros, 2011), and predation at the nest by the sugar glider Petaurus breviceps, a native Australian marsupial introduced to Tasmania (Stojanovic et al., 2014). The Swift Parrot Recovery Team was established in 1995 and has 12 members. This team has had the same leader since 2004.

Carnaby's black-cockatoo is a large black cockatoo with white tail panels and is endemic to south-west Western Australia. It breeds primarily in woodlands and scrubs in the semiarid interior and moves to the coastal plain in winter (Saunders, 1979). It is categorized as Endangered under both the IUCN criteria (BirdLife International, 2013) and the Environment Protection and Biodiversity Conservation Act 1999 (Department of the Environment, 1999). The decline of Carnaby's black-cockatoo is attributed to loss of habitat as a result of clearing or degradation, competition for nest sites, loss of individuals as a result of illegal activities (shooting to protect crops and taking birds for avicultural markets), collisions with motor vehicles, and disease (Department of Environment and Conservation, 2012). The Carnaby's Black-cockatoo Recovery Team was established in 1999. It had 15 members and had the same leader since 2005.

Baudin's black-cockatoo is another large white-tailed black cockatoo endemic to south-western Australia, where it is largely confined to the tall wetter forests (Campbell \& Saunders, 1976). Most early accounts of white-tailed blackcockatoos did not distinguish between Baudin's and Carnaby's (Higgins, 1999). Baudin's black-cockatoo is categorized as Endangered under the IUCN criteria (BirdLife International, 2012) and Vulnerable under the Environment Protection and Biodiversity Conservation Act 1999 (Department of the Environment, 1999). The threats identified for Baudin's black-cockatoo are illegal shooting by orchardists, habitat loss, nest hollow shortage and competition for available nest hollows (Chapman, 2008). A Recovery Team was established for Baudin's black-cockatoo in 2005; this team also covered other threatened forest cockatoos. It comprised 11 members and had the same leader since its inception.

\section{Stakeholder selection}

For each of the six case studies the relevant social networks all contained stakeholders within a well-defined management area, making identification of the stakeholders relatively straightforward. The social networks were identified by focusing on the individuals directly involved in the 
TABLE 2 UCINET threshold scores used to characterize network metrics.

\begin{tabular}{|c|c|c|c|}
\hline Attribute & Metric & Negative & Positive \\
\hline \multirow[t]{2}{*}{ Collective memory/experiences } & Density & 0.15 & 0.39 \\
\hline & Reachability & $79 \%$ & $100 \%$ \\
\hline \multirow[t]{2}{*}{ Diversity } & Betweenness (no. of subgroups) & 4 & 9 \\
\hline & Density & 0.39 & 0.15 \\
\hline \multirow[t]{2}{*}{ Redundancy } & Betweenness (of single actors) & $53 \%$ & $26 \%$ \\
\hline & Density & 0.15 & 0.39 \\
\hline \multirow[t]{3}{*}{ Learning } & Betweenness (no. of subgroups) & 4 & 9 \\
\hline & Centralization & $69 \%$ & $13 \%$ \\
\hline & Reachability & $79 \%$ & $100 \%$ \\
\hline \multirow[t]{3}{*}{ Adaptive capacity } & Centralization & $13 \%$ & $69 \%$ \\
\hline & Density & 0.39 & 0.15 \\
\hline & Reachability & $79 \%$ & $100 \%$ \\
\hline \multirow[t]{2}{*}{ Trust } & Density & 0.39 & 0.15 \\
\hline & Betweenness (no. of subgroups) & 9 & 4 \\
\hline
\end{tabular}

management of the case study taxa, starting with formal recovery teams, if they existed, and adding new individuals if and when they emerged (through snowball sampling). For those taxa without recovery teams, individuals actively involved in the conservation efforts were identified from relevant literature, through contacts with government officers responsible for taxon conservation, and through snowball sampling. Semi-structured interviews were undertaken with the identified stakeholders, providing insights into stakeholder relationships and triangulation of data collected in networks (Reed et al., 2009).

\section{Stakeholder analysis}

TQH conducted interviews with stakeholders in person or by telephone, and included questions involving free recall (Wasserman \& Faust, 1994), to determine with whom the stakeholders interacted, the frequency of interactions and the strength of relationships. The definition of what constituted an interaction was left to the interviewee but was primarily focused on communication, and included face-toface meetings (especially for species for which there were recovery teams), shared field experience, telephone conversations and e-mail contact. We interviewed 55 informants with relevant experience. The interviews comprised directed but open-ended questions (Holmes, 2014) focusing on the role of the interviewee and their colleagues in the recovery of the case study taxon. For logistical and timing reasons some members of the networks were unavailable for interview. In such cases their position in the network was determined from other network members, thus potentially making the effect of such omissions negligible (Kossinets, 2006). Others were excluded based on the evidently low salience of their involvement.

The data concerning social network participation and linkages for each of the case study taxa were analysed using UCINET 6 (Borgatti et al., 2002), which is specifically designed for mapping and measuring the characteristics of social networks. The intensity of network metrics was characterized on the basis of Table 2.

\section{Results}

Of the 55 informants who were interviewed, 36 were members of recovery teams, distributed as follows across the individual teams: orange-bellied parrot, $80 \%$; swift parrot, 78\%; Carnaby's black-cockatoo, 60\%; and Baudin's blackcockatoo, $73 \%$. This represents a reasonable proportion of key informants given that the accuracy of identifying central nodes from randomly generated social networks declines predictably and monotonically with inclusion (Borgatti et al., 2006), and the non-response effect was likely to have been balanced by reciprocal nominations from other team members (Kossinets, 2006). We interviewed 19 individuals who were not on recovery teams but were directly involved in the recovery of the case study taxa, providing additional data for collaborations and social network analysis.

Analysis of the potentially influential attributes of networks (Table 3 ) indicates that there is substantial variation in most characteristics across the various taxa. Comparisons of the attributes indicated that many of these factors were likely to have had a positive influence on the effectiveness of networks (Table 4), but there was high variability. The networks themselves varied substantially, from sparse and small to large and complex (Fig. 1), with each characteristic having potential strengths and weaknesses. Size alone can affect some metrics (Prell, 2012): the Alligator Rivers yellow chat network has only 72 possible linkage pairs among its nine members, whereas there are 1,722 possible linkages among the 42 members of the Carnaby's Black-Cockatoo Recovery Team (Table 3). All networks included more 
TABLE 3 Attributes of the social networks for the six study species.

\begin{tabular}{|c|c|c|c|c|c|c|}
\hline Network variables & $\begin{array}{l}\text { Alligator Rivers yellow } \\
\text { chat Epthianura crocea } \\
\text { tunneyi }\end{array}$ & $\begin{array}{l}\text { Capricorn yel- } \\
\text { low chat } \\
\text { Epthianura cro- } \\
\text { cea macgregori }\end{array}$ & $\begin{array}{l}\text { Orange-bellied parrot } \\
\text { Neophema chrysogaster }\end{array}$ & $\begin{array}{l}\text { Swift parrot } \\
\text { Lathamus discolor }\end{array}$ & $\begin{array}{l}\text { Carnaby's black- } \\
\text { cockatoo } \\
\text { Calyptorhynchus } \\
\text { latirostris }\end{array}$ & $\begin{array}{l}\text { Baudin's black- } \\
\text { cockatoo } \\
\text { Calyptorhynchus } \\
\text { baudinii }\end{array}$ \\
\hline No. of nodes & 9 & 15 & 28 & 23 & 42 & 24 \\
\hline $\begin{array}{l}\text { Possible links between node } \\
\text { pairs }\end{array}$ & 72 & 210 & 756 & 506 & 1722 & 552 \\
\hline Density $^{1}$ (no. of ties) & $0.39(28)$ & $0.19(39)$ & $0.25(189)$ & $0.22(113)$ & $0.15(257)$ & $0.25(138)$ \\
\hline Reachability $^{2}$ & $100 \%$ & $100 \%$ & $\begin{array}{l}79 \% \text { reachable by } 96 \% \& 21 \% \\
\text { reachable by } \leq 18 \%\end{array}$ & $100 \%$ & $100 \%$ & $100 \%$ \\
\hline Mean geodesic distance ${ }^{3}$ & 1.71 & 2.12 & 2.06 & 2.01 & 2.37 & 1.87 \\
\hline Network centralization index ${ }^{4}$ & $49 \%$ & $69 \%$ & $13 \%$ & $43 \%$ & $19 \%$ & $49 \%$ \\
\hline \multicolumn{7}{|l|}{ Betweenness index } \\
\hline Range & $0-30$ & $0-131$ & $0-109$ & $0-212$ & $0-365$ & $0-256$ \\
\hline Mean & 6 & 15 & 23 & 22 & 55 & 20 \\
\hline Sum & 51 & 218 & 634 & 502 & 2319 & 480 \\
\hline$\%$ scored 0 & 33 & 53 & 39 & 52 & 26 & 46 \\
\hline No. of subgroups ${ }^{5}$ & 4 & 4 & 7 & 6 & 9 & 7 \\
\hline
\end{tabular}

${ }^{1}$ Density equals the sum of the ties present divided by the number of possible ties.

${ }^{2}$ The percentage of actors reachable by all others.

${ }^{3}$ If the network is moderately dense the geodesic distances are generally small, suggesting that information may travel more rapidly in the network.

${ }^{4}$ The higher the value the more centralized the network.

${ }^{5}$ Groups of actors that are well-connected to each other, but with few connections between the groups. 
TABLE 4 Potential influences (+, positive; -, negative) of the network attributes on the social networks for each of the six study species. Strength of attribute is indicated by intensity of shading.

\begin{tabular}{|c|c|c|c|c|c|c|c|}
\hline Attribute & Metric & $\begin{array}{l}\text { Alligator } \\
\text { Rivers yellow } \\
\text { chat }\end{array}$ & $\begin{array}{l}\text { Capricorn } \\
\text { yellow chat }\end{array}$ & $\begin{array}{l}\text { Orange-bellied } \\
\text { parrot }\end{array}$ & $\begin{array}{l}\text { Swift } \\
\text { parrot }\end{array}$ & $\begin{array}{l}\text { Carnaby's } \\
\text { black-cockatoo }\end{array}$ & $\begin{array}{l}\text { Baudin's } \\
\text { black-cockatoo }\end{array}$ \\
\hline \multirow{4}{*}{$\begin{array}{l}\text { Collective mem- } \\
\text { ory/experiences } \\
\text { Diversity }\end{array}$} & Density & + & - & - & - & - & - \\
\hline & Reachability & + & + & - & + & + & + \\
\hline & $\begin{array}{l}\text { No. of } \\
\text { subgroups }\end{array}$ & - & - & + & + & + & + \\
\hline & Density & - & - & + & + & + & + \\
\hline \multirow[t]{2}{*}{ Redundancy } & Betweenness & - & - & - & - & + & - \\
\hline & Density & + & - & - & - & - & - \\
\hline \multirow[t]{3}{*}{ Learning } & Betweenness & - & + & - & - & + & - \\
\hline & Centralization & $+1-$ & - & + & $+1-$ & + & $+1-$ \\
\hline & Reachability & + & + & - & + & + & + \\
\hline \multirow{3}{*}{$\begin{array}{l}\text { Adaptive } \\
\text { capacity }\end{array}$} & Centralization & $+1-$ & + & - & $+1-$ & - & $+1-$ \\
\hline & Density & - & + & + & + & + & + \\
\hline & Reachability & + & + & - & + & + & + \\
\hline \multirow[t]{2}{*}{ Trust } & Betweenness & - & + & - & - & - & - \\
\hline & Density & + & - & - & - & - & - \\
\hline
\end{tabular}

members than illustrated in Fig. 1, but those additions would be pendants (i.e. nodes connected to the network by a single tie). This is not to deny the potential significance of these nodes in occasionally undertaking supportive actions for management of the species, but the interview data established their peripheral role.

\section{Alligator Rivers yellow chat}

The small network for this taxon had weak ties because of the infrequency of interactions between the actors, and the lack of coordination. There were no actions being implemented for the recovery of the taxon at the time of the interviews.

\section{Capricorn yellow chat}

This relatively small network was characterized by a low density of ties and high centralization. Although four subgroups were identified, all were connected to one centralized actor. Only three individuals were not linked directly to that actor, and each was separated from the actor by only one node. Without a formal recovery team that meets regularly, the network relied on funded projects to undertake conservation actions and maintain communication among network members. The lack of regular meetings and the reliance on informal and opportunistic communications could be attributed to not having a formal recovery team, despite having a recovery plan.

\section{Orange-bellied parrot}

Diversity within this network was high, resulting from a degree of separation of groups and low overall density of ties.
The network had low density, with some actors not reachable by others, high betweenness (linkage) scores of some actors and a low level of centralization. As a subgroup the recovery team was characterized by strong ties between group members, but recovery team members recognized others as part of a broader network with interests in conservation of the parrot.

\section{Swift parrot}

All actors in this network were reachable by others but density was relatively low. The data suggested diversity was likely to be high, resulting from a degree of separation of subgroups supported by a low density of ties, with some actors having high betweenness scores. Centralization was neither high nor low. This network had weak ties to the timber industry despite the industry's importance to conservation of the parrot in its breeding grounds.

\section{Carnaby's black-cockatoo}

Everyone in the network was reachable by others but there was a low density of ties, numerous subgroups and a low level of centralization. The betweenness scores suggested high redundancy. There were many strong ties throughout the network, including beyond the recovery team.

\section{Baudin's black-cockatoo}

This network resembled the swift parrot network. All actors were reachable by others but density was relatively low and there was a low density of ties with well-separated subgroups. Some actors had high betweenness scores but 


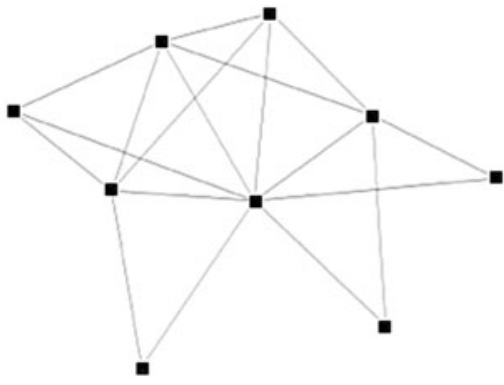

(a) Alligator Rivers yellow chat

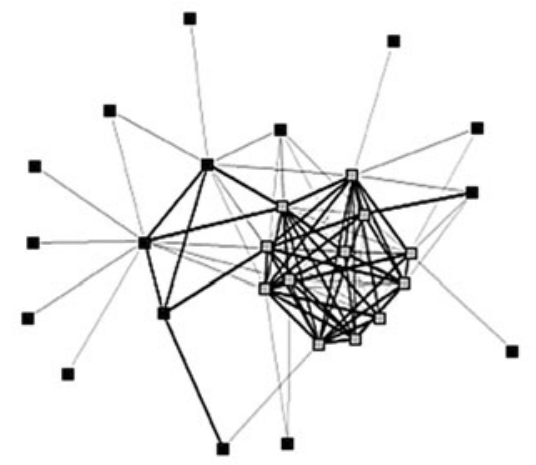

(c) Orange-bellied parrot

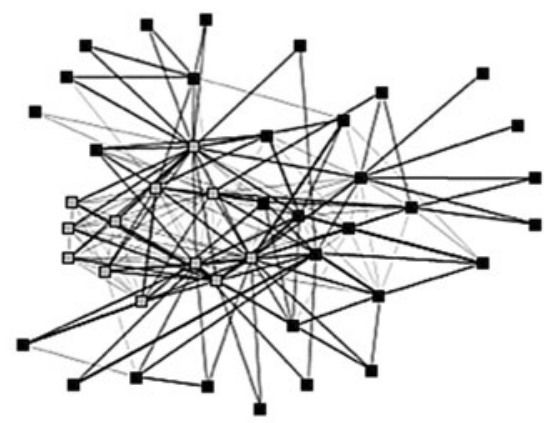

(e) Carnaby's black-cockatoo

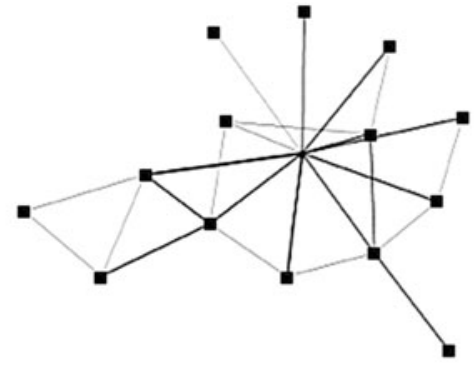

(b) Capricorn yellow chat

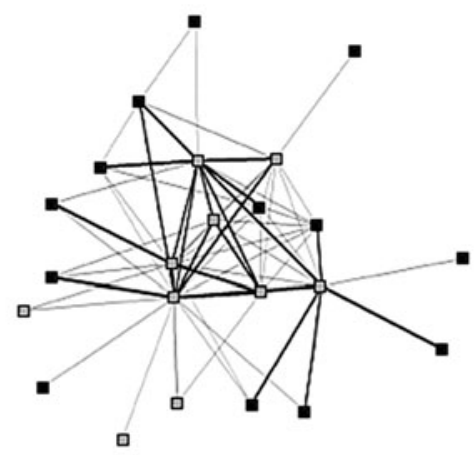

(d) Swift parrot

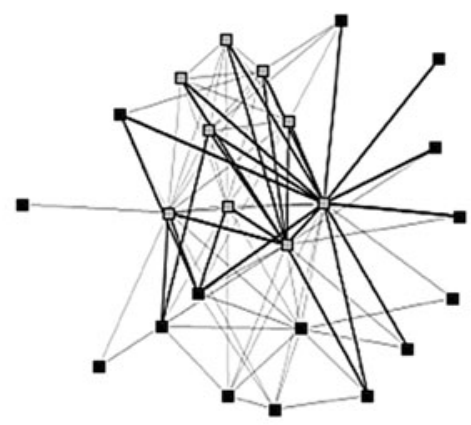

(f) Baudin's black-cockatoo
FIG. 1 Management networks for six threatened Australian bird taxa: (a) Alligator Rivers yellow chat Epthianura crocea tunneyi, (b) Capricorn yellow chat Epthianura crocea macgregori, (c) orange-bellied parrot Neophema chrysogaster, (d) swift parrot Lathamus discolor, (e) Carnaby's black-cockatoo Calyptorhynchus latirostris and (f) Baudin's black-cockatoo Calyptorhynchus baudinii. Square nodes represent the individuals in the network; black nodes are recovery team members and grey nodes others. Lines represent ties between nodes, with thicker lines signifying stronger ties, based on individuals' responses regarding the importance of others in the network. centralization was neither high nor low. The network was characterized by the dominance of state government representatives (67\%). Illegal killing of cockatoos by orchardists is considered to be a significant threat (Chapman, 2008) but although there had been ad hoc engagement with the fruitgrowing industry in the past, maintaining communication had proved difficult and industry representation was lacking, thus limiting expectations of progress in threat mitigation.

\section{Discussion}

The coordination that is necessary for networks to contribute effectively to the conservation of a taxon was lacking for the Alligator Rivers yellow chat. A separate analysis of the values people hold for this subspecies found that, despite legislative obligations, no-one felt any individual responsibility for the subspecies' conservation (Ainsworth, 2014; Ainsworth et al., 2015). It may not be a coincidence that there appears to have been substantial, previously undetected, decline in the last decade (Kyne \& Jackson, 2015).

All other taxa had a key individual or a recovery team that facilitated coordination. The Capricorn yellow chat had an individual champion who undertook actions, facilitated actions and/or advocated for actions to be implemented. However, high scores for centralization and density are not inherently conducive to good outcomes (Prell et al., 2009), as reliance on an individual champion is tenuous and can be characterized by ad hoc actions, meetings and exchanges of information. The network for the Capricorn yellow chat showed strong adaptive capacity, the only attribute that scored positively among all measures for the two networks that did not have recovery teams. 
In cases where recovery teams had been established to undertake coordination of taxon conservation, subgroups constituted the basis of relevant networks. These subgroups were well-connected, had high densities of ties, and the actors within them had higher betweenness scores, an attribute that generally contributes positively to the effectiveness of networks (Prell et al., 2009). All the networks with recovery teams had consistently high levels of diversity of actors, who probably contributed different knowledge to the networks and thus increased the potential for innovation (Bodin et al., 2006). All but one of the networks with teams demonstrated strong adaptive capacity, suggesting greater ability to manage new knowledge of the taxa more effectively or accommodate new information on threats and changing conditions. These three networks also showed strong learning capacities, facilitating increased and improved knowledge.

The presence of a recovery team within a network provided focus, encouraged coordination of actions and facilitated the flow of information within the network and beyond. Other benefits arose because the attributes of effective recovery teams are useful for the functioning of networks (Holmes, 2014); for example, the practical commitment for a recovery team to meet on a regular basis increases the likelihood of communication extending to others in the network. If a recovery team has a broad representation of stakeholders, this can also be beneficial for the diversity and learning of the network (Bodin et al., 2006). Maintaining networks requires investment of time and energy (Cross et al., 2002a). The weaknesses of networks with recovery teams may include the potential for a lack of trust and having little redundancy (replication of linkages), which are characterized by having low betweenness scores and low density (Bodin et al., 2006).

Information, resources and perspectives tend to be more similar within, but different between, social networks. To improve the diversity of information and perspectives, stakeholder representation and potential access to more resources, recovery team membership could be strengthened by becoming more representative of the various stakeholder clusters within the social networks (Reagans et al., 2004).

Social network analysis has been used extensively for the purposes of diagnosing and strengthening organizations (Cross et al., 2002b; Scott, 2011). Each of the groups responsible for, or with an interest in, conservation of the six threatened species examined here could benefit from understanding the vulnerabilities inherent in current network structures and examining potential approaches to strengthening them. Recovery plans aim to facilitate recovery activities by providing a planned and logical framework for action, including specific, measurable, achievable, relevant and time-bound objectives. Social networks could be honed to improve communication, decision making, coordination and implementation of conservation actions (Vance-Borland \& Holley, 2011; Mills et al., 2014). This can be done by recovery teams recognizing the significance of social networks, investing resources to improve understanding of their existing networks and undertaking analysis to develop favourable capabilities by building on their strengths and minimizing weaknesses. Such analysis could be undertaken both proactively, when initiating conservation programmes for threatened species, and retrospectively for programmes that are already established. The tools of analysis are readily available, along with guidelines on how to interpret the results. As is evident from our findings, strengths and weaknesses of network structures are often two sides of the same coin, and the ideal network requires a balance tailored to the problem at hand rather than simply an increase in resources. In fact network structures need to be optimized according to the resources that may be available.

Social network analysis can be a powerful managerial tool for identifying issues that are hindering the effectiveness and capacity of a group, and to identify the specific behaviours and organizational elements that require modification if the group is to deliver conservation action effectively. An effective social network is likely to be particularly important where species conservation is underfunded and relies heavily on volunteers. This study investigated the traits that can influence the efficiency and effectiveness of social networks for six threatened bird taxa. We identified potential strengths and weaknesses in each of the networks and demonstrated how attributes of the social networks associated with each bird have the potential to influence outcomes for the conservation of threatened species. Investment in social network analysis of recovery teams, or an understanding of social network theory when creating such teams, offers the potential to increase their effectiveness, especially if resources are constrained.

\section{Acknowledgements}

We are indebted to all those working on the recovery of threatened birds across Australia who participated voluntarily in this study, and to Dr Gillian Ainsworth for collaboration in the field. We thank Claire Johnston for assistance with the figure. We obtained ethics approval for the study from the Behavioural and Social Sciences Ethical Review Committee of the University of Queensland to undertake the study. Funding was provided by the Australian Research Council as part of project LPo990395, BirdLife Australia and Biosis.

\section{Author contributions}

TQH undertook the interviews, performed the primary analysis and drafted the initial manuscript, BWH, HPP and STG contributed to research design, and STG and BWH finalized the article. 


\section{References}

Adger, W.N., Brown, K. \& Tomprins, E.L. (2005) The political economy of cross-scale networks in resource co-management. Ecology and Society, 10, http://www.ecologyandsociety.org/volio/ iss2/art9.

Ainsworth, G.B. (2014) Valuing birds: understanding the relationship between social values and the conservation of Australian threatened avifauna. PhD thesis. Charles Darwin University, Darwin, Australia.

Ainsworth, G.B., Aslin, H.J., Weston, M.A. \& Garnett, S.T. (2016) Do social values influence levels of conservation effort in threatened species? The case of two Australian chats. Oryx, 50, 636645 .

Alexander, S.M., Armitage, D. \& Charles, A. (2015) Social networks and transitions to co-management in Jamaican marine reserves and small-scale fisheries. Global Environmental Change, 35 213-225.

Armitage, D., De Lö̈, R. \& Plummer, R. (2012) Environmental governance and its implications for conservation practice. Conservation Letters, 5, 245-255.

Armstrong, M. (2004) The Yellow Chat Epthianura crocea tunneyi in Kakadu National Park. Parks Australia (North), Darwin, Australia.

Bird Life International (2012) Zanda baudinii. The IUCN Red List of Threatened Species 2013: e.T22684727A38973933. Http://dx.doi. org/10.2305/IUCN.UK.2012-1.RLTS.T22684727A38973933.en [accessed 16 June 2016].

Birdife International (2013) Zanda latirostris. The IUCN Red List of Threatened Species 2013: e.T22684733A48062560. Http://dx. doi.org/10.2305/IUCN.UK.2013-2.RLTS.T22684733A48062560.en [accessed 16 June 2016].

BirdLife International (2015a) Lathamus discolor. The IUCN Red List of Threatened Species 2015: e.T22685219A83985233. http://dx.doi org/10.2305/IUCN.UK.2015-4.RLTS.T22685219A83985233.en [accessed 16 June 2016].

Birdife International (2015b) Neophema chrysogaster. The IUCN Red List of Threatened Species 2015: e.T22685203A79818705. Http:// dx.doi.org/10.2305/IUCN.UK.2015-4.RLTS.T22685203A79818705.en [accessed 16 June 2016].

Bodin, Ö. \& Crona, B.I. (2009) The role of social networks in natural resource governance: what relational patterns make a difference? Global Environmental Change, 19, 366-374

Bodin, Ö., Crona, B. \& Ernstson, H. (2006) Social networks in natural resource management: what is there to learn from a structural perspective? Ecology and Society, 11, http://www. ecologyandsociety.org/vol11/iss2/resp2/.

Borgatti, S.P., Carley, K.M. \& Krackhardt, D. (2006) On the robustness of centrality measures under conditions of imperfect data. Social Networks, 28, 124-136.

Borgatti, S.P., Everett, M.G. \& Freeman, L.C. (2002) Ucinet 6 for Windows: Software for Social Network Analysis. Analytic Technologies, Lexington, USA.

Bottrill, M.C., Walsh, J.C., Watson, J.E.M., Joseph, L.N., Ortega-Argueta, A. \& Possingham, H.P. (2011) Does recovery planning improve the status of threatened species? Biological Conservation, 144, 1595-1601.

Butts, C.T. (2009) Revisiting the foundations of network analysis. Science, 325, 414-416.

Campbell, N.A. \& SAunders, D.A. (1976) Morphological variation in the white-tailed black cockatoo, Calyptorhynchus baudinii, in Western Australia: a multivariate approach. Australian Journal of Zoology, 24, 589-595.

Chapman, T. (2008) Forest black cockatoo (Baudin's cockatoo Calyptorhynchus baudinii and forest red-tailed black-cockatoo
Calyptorhynchus banksii naso) recovery plan. Western Australia Department of Environment and Conservation, Perth, Australia.

Chilvers, J. \& Evans, J. (2009) Understanding networks at the science-policy interface. Geoforum, 40, 355-362.

Commonwealth Threatened Species Scientific Committee (2008) Approved Conservation Advice for Epthianura crocea tunneyi (Yellow Chat (Alligator Rivers)). Http://www.environment.gov.au/ cgi-bin/sprat/public/publicspecies.pl?taxon_id=67089 [accessed 27 December 2015].

Crona, B. \& Hubacek, K. (2010) The right connections: how do social networks lubricate the machinery of natural resource governance? Ecology and Society, 15, http://www.ecologyandsociety. org/vol15/iss4/art18/.

Cross, R., Borgatti, S.P. \& Parker, A. (2002a) Making invisible work visible: using social network analysis to support strategic collaboration. California Management Review, 44, 25-46.

Cross, R., Nohria, N. \& Parker, A. (2002b) Six myths about informal networks-and how to overcome them. Sloan Management Review, 43, 67-75.

Department of the Environment (1999) Environment Protection and Biodiversity Conservation Act 1999. Https://www.environment. gov.au/epbc [accessed 16 June 2016].

Department of Environment and Conservation (2012) Carnaby's Cockatoo (Calyptorhynchus latirostris) Recovery Plan. Department of Environment and Conservation, Perth, Australia.

Department of Sustainability, Environment, Water, Population and Communities (2013) Recovery plans. Http:// www.environment.gov.au/biodiversity/threatened/recovery.html [accessed 27 December 2015].

Fowler, J.H. \& Christakis, N.A. (2008) Dynamic spread of happiness in a large social network: longitudinal analysis over 20 years in the Framingham Heart Study. British Medical Journal, 337, a2338.

Garnett, S., Szabo, J. \& Dutson, G. (2011) Action Plan for Australian Birds 2010. CSIRO, Melbourne, Australia.

Higgins, P. (ed.) (1999) Handbook of Australian, New Zealand and Antarctic Birds. Volume 4. Parrots to Dollarbird, Oxford University Press, Melbourne, Australia.

Holland, J. (2007) Tools for Institutional, Political, and Social Analysis of Policy Reform: A Sourcebook for Development Practitioners. The World Bank, Washington, DC, USA.

Holmes, T.Q. (2014) Analysis of the institutional arrangements for the management of Australia's threatened birds. $\mathrm{PhD}$ thesis. University of Queensland, St Lucia, Australia.

Houston, W. \& Melzer, A. (2008) Yellow Chat (Capricorn subspecies) Epthianura crocea macgregori Recovery Plan. Report to Department of the Environment, Water, Heritage and the Arts, Canberra. Queensland Environmental Protection Agency, Brisbane, Australia.

Jepson, P. (2016) Saving a species threatened by trade: a network study of Bali starling Leucopsar rothschildi conservation. Oryx, 50, 480-488.

Jepson, P., Marua, M. \& Buckingham, M. (2011) What is a conservation actor? Conservation and Society, 9, 229-235.

KEAST, A. (1958) The relationship between seasonal movements and the development of geographic variation in the Australian Chats, (Epthianura Gould and Ashbyia North (Passeres: Muscicapidae, Malurinae)). Australian Journal of Zoology, 6, 53-68.

Keast, R., Mandell, M.P. \& Agranoff, R. eds (2014) Network Theory in the Public Sector: Building New Theoretical Frameworks. Routledge, London, UK.

Koliba, C.J., Mills, R.M. \& Zia, A. (2011) Accountability in governance networks: an assessment of public, private, and nonprofit emergency management practices following Hurricane Katrina. Public Administration Review, 71, 210-220. 
Kossinets, G. (2006) Effects of missing data in social networks. Social Networks, 28, 247-268.

Kyne, P.M. \& JACKSON, M.V. (2015) Surveys for Yellow Chat Epthianura crocea tunneyi on the South Alligator River Floodplain, Kakadu National Park, 2014. A report to Parks Australia, Darwin, Australia.

Lauber, T.B., Decker, D.J. \& Knuth, B.A. (2008) Social networks and community-based natural resource management. Environmental Management, 42, 677-687.

Lukasiewicz, A., Davidson, P., Syme, G.J. \& Bowmer, K.H. (2013) How the social construction of the environment affects people's reactions to water policy. Australasian Journal of Environmental Management, 20, 179-192.

Mills, M., Álvarez-Romero, J.G., Vance-Borland, K., Cohen, P., Pressey, R.L., Guerrero, A.M. \& Ernstson, H. (2014) Linking regional planning and local action: towards using social network analysis in systematic conservation planning. Biological Conservation, 169, 6-13.

Orange-bellied Parrot Recovery Team (2006) National Recovery Plan for the Orange-Bellied Parrot. Department of Primary Industries and Water, Hobart, Australia.

Ostrom, E. (2005) Understanding Institutional Diversity. Princeton University Press, Princeton, USA.

OTte, E. \& Rousseau, R. (2002) Social network analysis: a powerful strategy, also for the information sciences. Journal of Information Science, 28, 441-453.

Prell, C. (2012) Social Network Analysis: History, Theory \& Methodology. SAGE Publications Ltd, London, UK.

Prell, C., HubaceK, K. \& Reed, M. (2009) Stakeholder analysis and social network analysis in natural resource management. Society \& Natural Resources, 22, 501-518.

Reagans, R., Zuckerman, E. \& McEvily, B. (2004) How to make the team: social networks vs. demography as criteria for designing effective teams. Administrative Science Quarterly, 49, 101-133.

Reed, M.S., Graves, A., Dandy, N., Posthumus, H., Hubacek, K., Morris, J. et al. (2009) Who's in and why? A typology of stakeholder analysis methods for natural resource management. Journal of Environmental Management, 90, 1933-1949.

SAUndERS, D.A. (1979) The availability of tree hollows for use as nest sites by white-tailed black cockatoos. Wildlife Research, 6, 205-216.

Saunders, D.L. \& Tzaros, C.L. (2011) National Recovery Plan for Swift Parrot Lathamus discolor. Birds Australia, Melbourne, Australia.
Schodde, R. \& Mason, I.J. (1999) The Directory of Australian Birds: Passerines. CSIRO, Melbourne, Australia.

ScotT, J. (2011) Social network analysis: developments, advances, and prospects. SOCNET, 1, 21-26.

Stojanovic, D., Webb, M.H., Alderman, R., Porfirio, L.L. \& Heinsohn, R. (2014) Discovery of a novel predator reveals extreme but highly variable mortality for an endangered migratory bird. Diversity and Distributions, 20, 1200-1207.

Stoker, G. (1998) Governance as theory: five propositions. International Social Science Journal, 50, 17-28.

Swift Parrot Recovery Team (2001) National Swift Parrot Recovery Plan 2001-2005. Department of Primary Industries, Water and Environment, Hobart, Australia.

Tompkins, E.L. \& Adger, W.N. (2004) Does adaptive management of natural resources enhance resilience to climate change? Ecology and Society, 9, http://www.ecologyandsociety.org/volg/iss2/art1o.

Vance-Borland, K. \& Holley, J. (2011) Conservation stakeholder network mapping, analysis, and weaving. Conservation Letters, 4 , 278-288.

Wasserman, S. \& Faust, K. (1994) Social Network Analysis: Methods and Applications. Cambridge University Press, Cambridge, UK.

Wey, T., Blumstein, D.T., Shen, W. \& Jordán, F. (2008) Social network analysis of animal behaviour: a promising tool for the study of sociality. Animal Behaviour, 75, 333-344.

Woodward, E. (2008) Social networking for Aboriginal land management in remote northern Australia. Australasian Journal of Environmental Management, 15, 241-252.

\section{Biographical sketches}

Tim Holmes is a former senior public servant specializing in conservation management, with a particular focus on the management of threatened bird species. BRIAN HEAD's recent work includes projects on the contribution of social science to complex problem-solving, and the role of rigorous evidence in policymaking. Hugh Possingham directs the Australian Research Council Centre of Excellence for Environmental Decisions and the National Environmental Science Programme Threatened Species Recovery Hub. Stephen GarnetT has worked on Australian threatened birds for the last 30 years. 